CAIO HENRIQUE YOSHIKAWA

A história da governança corporativa contemporânea das instituições financeiras no Brasil

Dissertação de Mestrado

Orientador: Professor Doutor Carlos Pagano Botana Portugal Gouvêa

UNIVERSIDADE DE SÃO PAULO

FACULDADE DE DIREITO

São Paulo - SP

2017 
CAIO HENRIQUE YOSHIKAWA

\section{A história da governança corporativa contemporânea das instituições financeiras no}

\section{Brasil}

Dissertação de mestrado apresentada à Banca Examinadora do Programa de PósGraduação em Direito, da Faculdade de Direto da Universidade de São Paulo, como requisito parcial para a obtenção do título de Mestre em Direito, na área de concentração Direito Comercial, sob a orientação do Professor Doutor Carlos Pagano Botana Portugal Gouvêa.

UNIVERSIDADE DE SÃO PAULO

FACULDADE DE DIREITO

São Paulo - SP 
Catalogação da Publicação

Serviço de Biblioteca e Documentação

Faculdade de Direito da Universidade de São Paulo

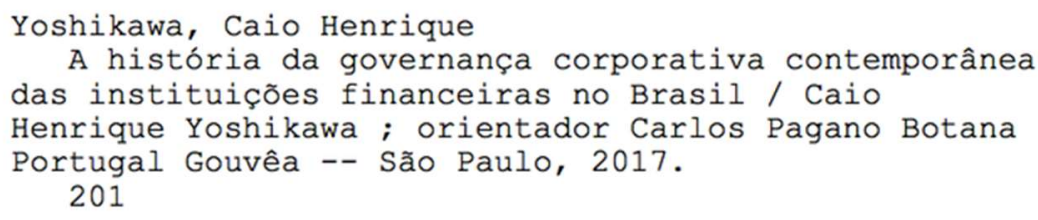

Dissertação (Mestrado - Programa de Pós-Graduação em Direito Comercial) - Faculdade de Direito, Universidade de São Paulo, 2017.

1. Instituições Financeiras. 2. Direito Comercial. 3. Direito Bancário. 4. Governança Corporativa. 5. História do Direito. I. Portugal Gouvêa, Carlos Pagano Botana, orient. II. Título. 


\section{CAIO HENRIQUE YOSHIKAWA}

A história da governança corporativa contemporânea das instituições financeiras no Brasil

Dissertação de mestrado apresentada ao Programa de Pós-graduação da Faculdade de Direto da Universidade de São Paulo como requisito parcial para a obtenção do título de Mestre em Direito.

Aprovado em:

Banca Examinadora:

Prof. Dr.:

Instituição:

Julgamento:

Prof. Dr.:

Instituição:

Julgamento:

Prof. Dr.:

Instituição:

Julgamento: 


\section{AGRADECIMENTOS}

Em primeiro lugar, agradeço a Jeová Deus por todas as boas dádivas com as quais tem me presenteado ao longo da minha vida.

Agradeço à minha mãe, Rosana Yoshikawa, e ao meu pai, Mario Yoshikawa, pelo amor inabalável com o qual têm me amparado por todos os meus 26 anos. Vocês são um presente, e é a vocês que eu dedico a minha dissertação. É um verdadeiro privilégio ser seu filho. Agradeço também aos meus familiares, meu avô João, minha avó Mitsue, minhas tias Rosângela, meus tios Wanderley e Marcelo, e meu primo Yan, por estarem sempre presentes.

Agradeço ao Professor Carlos Portugal Gouvêa, que não só foi o orientador do presente trabalho, como também um grande amigo e mentor na vida. Se este trabalho teve condições de ser produzido, é a ele a quem devo a honra. Os comentários feitos ao longo destes anos, sempre pertinentes, me ajudaram a desenvolver rigor científico um apreço pelo estudo cabal e interdisciplinar, e sempre repensar velhos dogmas acadêmicos (e, sobretudo, sua utilidade). Também, aos Professores Diogo Coutinho e Bruno Salama, que não só foram membros da banca examinadora, como me ajudaram ao longo de todo esse processo de pesquisa, em almoços, cafés e reuniões por meio de valiosos comentários. A sua disposição de tempo foi valiosa. Agradeço também à Professora Mariana Pargendler pelos preciosos materiais de pesquisa..

Agradeço também aos novos e velhos amigos de todo o tempo, pelo companheirismo sempre edificante e animador: Marcos Prado, Igor Oliveira, Edson Eusébio, Natan Carbone, Thiago e Izabela Araujo, Leandro Faria, Lizandra e Andrew Botelho. Como diria Provérbios 18:24, "há um amigo que se apega mais do que um irmão".

Muito obrigado aos amigos também do Largo de São Francisco e dos escritórios, cujos vínculos fraternais acabaram transcendendo o espaço social no qual nos conhecemos: Leandro Pérez, Igor Romitelli, Luis Al-Contar, Takashi Kojiro, Caio Dib, William Won Bae Kim, André Ziccardi, Rodrigo Cunha, Angelo Caldeira Ribeiro, Daniel Salgado, José Paulo Querino, William Yagihara, Ricardo Bellon, Lívia Trindade, Henrique Paiva, Karine 
Oliveira, Jefferson Souza, Leonardo Alvares, Bernardo Pascowitch e Rafael Bittencourt. Ao pessoal do PG Law, Apoena Becker, Amaury Oliva, Eduardo Fucci, Vanessa Lopes, Letícia Araújo e João Guerra, sempre muito compreensivos ao longo da escrita do presente trabalho.

Aos meus amigos, que desejou o tempo também que fossem colegas da pós-graduação na FDUSP, com quem sempre travei discussões intelectuais (e burocráticas), que com certeza foram muito valiosas e certamente me ajudaram a chegar até aqui: Raquel Pimenta, Rafael Bresciani, Bruno Becker, Lilian Melo, Helena Campos, Rodrigo Fialho, Pedro Schilling e Luiz Guilherme Valente.

Agradeço também aos comentários sempre importantes do Luiz Roberto de Assis e do Eduardo Salomão Neto, a quem devo muito em matéria de conhecimento de Direito Bancário. Agradeço também ao Bolívar Rocha Moura, ao Dr. Luiz Carlos Sturzenegger, e aos funcionários da Fundação Bradesco, que gentilmente me permitiram ter acesso a documentos antigos da história do Banco. 


\section{DEDICATÓRIA}

Este trabalho é dedicado aos meus pais, Rosana Santos Yoshikawa, e Mario Sumio Yoshikawa. 
"Sem orientação perita, o povo cai. Mas com muitos conselheiros há bons resultados." - Provérbios 11:4 (Tradução do Novo Mundo da Bíblia Sagrada). 


\section{RESUMO}

YOSHIKAWA, Caio Henrique. A história da governança corporativa das instituições financeiras no Brasil. 2017. Dissertação (Mestrado em Direito Comercial). Faculdade de Direito, Universidade de São Paulo, São Paulo, 2017.

A hipótese do presente trabalho é a de que o atual modelo jurídico da governança corporativa das instituições financeiras no Brasil, foi historicamente construído com base em quatro grandes momentos: (i) modernização do sistema financeiro nacional e do regime jurídico da insolvabilidade bancária; (ii) saneamento do sistema financeiro nacional, fortalecimento do Banco Central do Brasil e privatizações; (iii) internacionalização das instituições financeiras brasileiras e o impacto do direito estrangeiro; e (iv) resposta às evoluções tecnológicas e às demandas valorativas, ou expectativas sociais. Este trabalho visa demonstrar como este cainho histórico foi percorrido e, ao final, identificar a estrutura e as atuais práticas de governança corporativa de grandes bancos comerciais brasileiros.

Palavras-chave: Direito comercial; direito societário; direito bancário; direito econômico; governança corporativa; bancos. 


\begin{abstract}
YOSHIKAWA, Caio Henrique. A história da governança corporativa das instituições financeiras no Brasil. 2017. Dissertação (Mestrado em Direito Comercial). Faculdade de Direito, Universidade de São Paulo, São Paulo, 2017.

The hypothesis of this work is that the current legal model of corporate governance of financial institutions in Brazil was historically built through four moments: (i) modernization of the Brazilian financial system and the legal regime of banking insolvency; (ii) "sanitation" of the Brazilian financial system, strenghtening of the Central Bank of Brazil and privatizations; (iii) internationalization of Brazilian financial institutions and the impact of foreign laws; and (iv) governance responses to technologic changes and social values, or expectations. This work aims to demonstrate how this path was followed and finally, to identify the current corporate governance structure and practices of big Brazilian comercial banks.
\end{abstract}

Keywords: Commercial law; corporate law; banking law; financial regulation; economic law; corporate governance; banks. 


\section{SUMÁRIO}

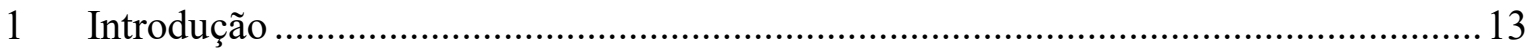

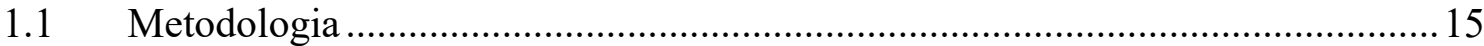

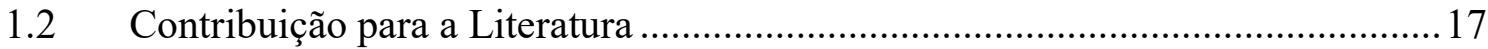

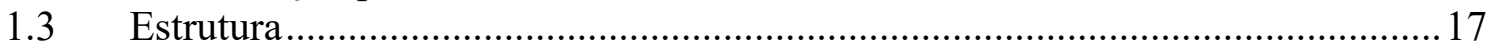

PARTE I - UMA INTRODUÇÃO AO ESTUDO DA GOVERNANÇA CORPORATIVA

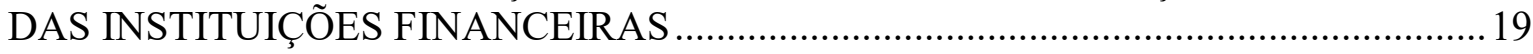

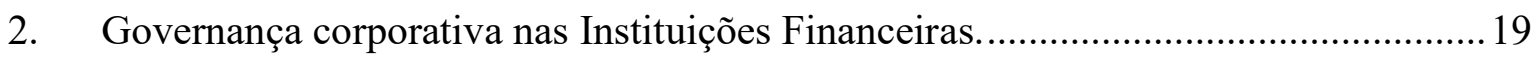

2.1 As particularidades da governança corporativa bancária ...................................19

2.2 Os grandes debates internacionais sobre governança corporativa nas instituições

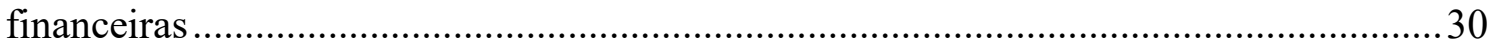

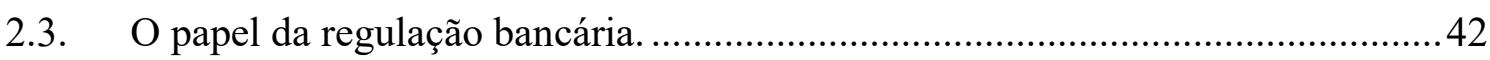

PARTE II - A CONSTRUÇÃO HISTÓRICA DA REGULAÇÃO DA GOVERNANÇA

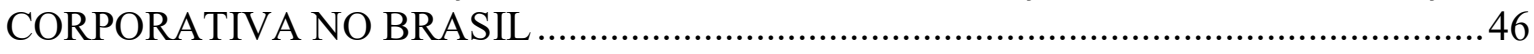

3. Momento I: Construção e Modernização.......................................................................46

3.1 A governança do Sistema Financeiro Nacional: a criação do Banco Central do

Brasil e do Conselho Monetário Nacional...................................................................49

3.2 A definição de "atividade privativa de instituições financeiras". ........................60

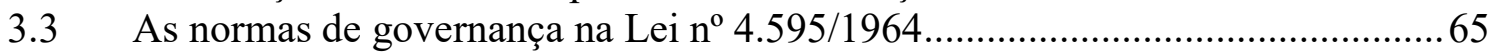

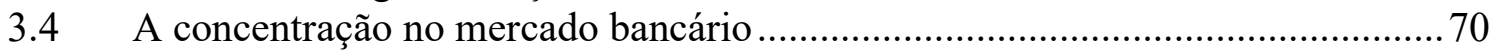

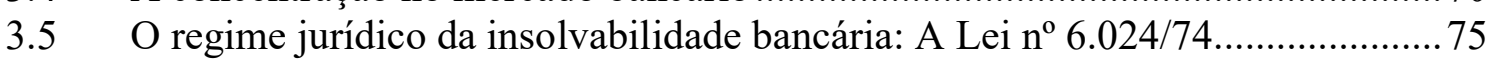

3.6 A responsabilidade dos administradores de instituições financeiras. .................. 79

4. Momento II: Saneamento e Privatização. A crise dos bancos estaduais, a lei dos crimes contra o Sistema Financeiro Nacional e o fortalecimento institucional do Banco

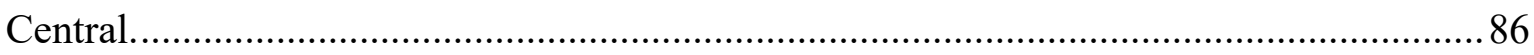

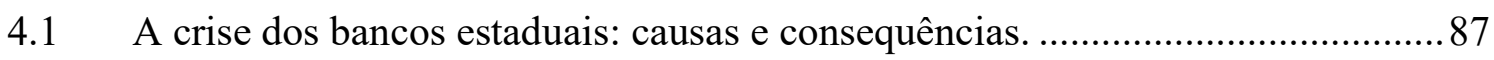

4.2 - A Lei dos Crimes contra o Sistema Financeiro Nacional. ....................................... 92

4.3 O Decreto-lei do RAET e a responsabilidade pessoal dos controladores............97

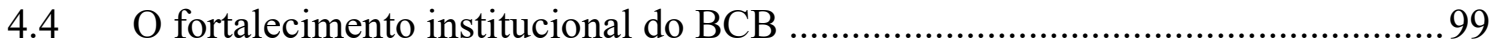

4.4.1 - Operações de socorro e imposição regulatória de reformas de governança

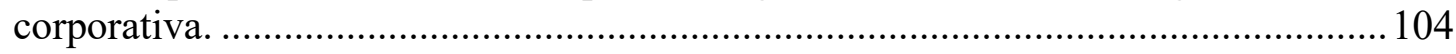

5. Momento II: Saneamento e Privatização. Anos 90: reforma do sistema bancário brasileiro e o fim da responsabilidade limitada do controlador......................................... 107

5.1 As reformas do sistema bancário: PROES, PROEF e PROER ..................... 112

5.2 A Lei ${ }^{\circ}$ 9.447/97: a ampliação dos poderes do Banco Central e o fim da responsabilidade limitada do controlador. .............................................................. 119

6. Momento III: Internacionalização. Anos 1990-2000: O impacto da regulação transnacional na governança corporativa dos bancos brasileiros. .................................... 122

6.1 Internacionalização da Regulação Bancária ................................................... 126

6.1.1 Os Acordos da Basileia, a Crise de 2008 e a Governança Corporativa das

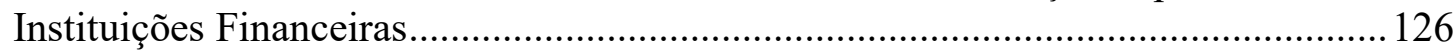

6.1.2 A difusão de boas práticas de governança corporativa no setor bancário. .... 134 
6.2 A internacionalização das instituições financeiras brasileiras e o impacto do Direito Estrangeiro.

6.2.1 A influência do direito norte-americano

7. Momento IV: Os Desafios Atuais da Governança Corporativa das Instituições Financeiras no Brasil. Inovação Tecnológica e Governança como Resposta aos Valores Sociais

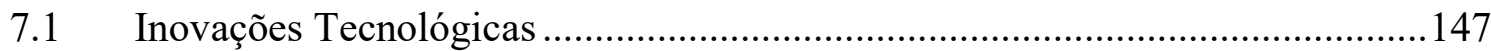

7.2 A Governança Corporativa e as Respostas aos Valores Sociais .........................149

PARTE III - O ESTÁGIO ATUAL DA GOVERNANÇA CORPORATIVA DAS INSTITUIÇÕES FINANCEIRAS NO BRASIL

8. A Governança Corporativa Contemporânea das Instituições Financeiras Brasileiras: O

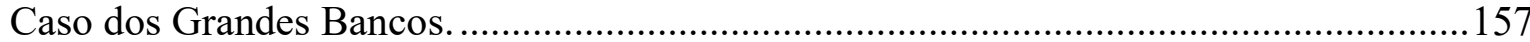

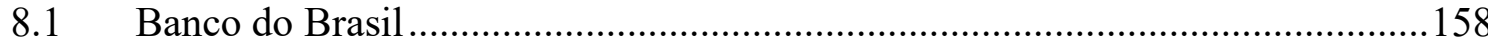

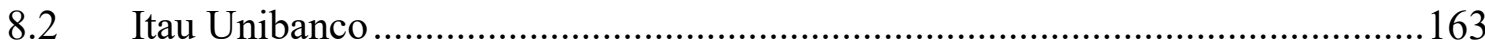

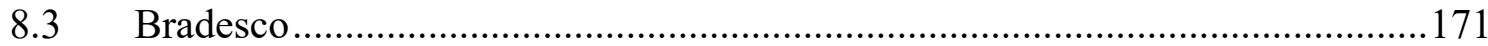

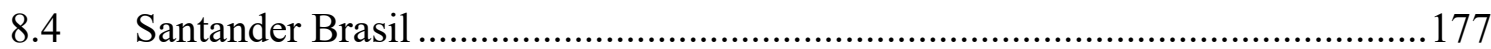

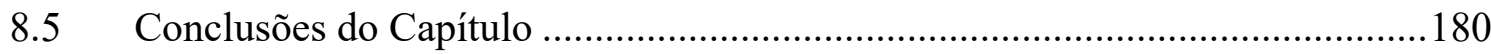

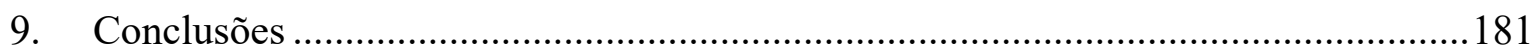

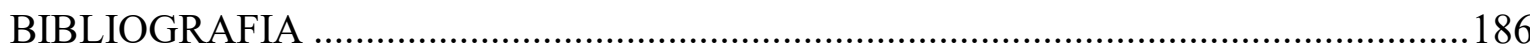




\section{Introdução}

A hipótese do presente trabalho é a de que o atual modelo de governança corporativa das instituições financeiras no Brasil foi construído historicamente com base em quatro grandes momentos: (i) modernização do sistema financeiro nacional; (ii) saneamento do sistema e privatizações; (iii) internacionalização; e (iv) resposta às evoluções tecnológicas e às demandas valorativas. Estes momentos serão, de agora em diante, denominados "Momento I", "Momento II", "Momento III" e "Momento IV", respectivamente. O modelo de governança corporativa das instituições financeiras no Brasil não se limita somente a componentes organizacionais internos, como estatutos, políticas e processos de tomada de decisão, mas também é composto por normas jurídicas, aqui denominadas "regulação da governança corporativa".

O Momento I consiste na formação do arcabouço jurídico do sistema financeiro brasileiro, motivado por um ímpeto de modernização das leis do sistema financeiro nacional, do mercado de capitais e das sociedades anônimas, com especial foco na Lei $\mathrm{n}^{\mathrm{o}} 4.595$, de 31 de dezembro de 1964, que criou o Conselho Monetário Nacional (CMN) e o Banco Central do Brasil (BCB), e na Lei ${ }^{\circ}$ 6.024, de 13 de março de 1974, que consolidou as regras sobre instituições financeiras em crise, bem como responsabilidade dos administradores. Estas leis determinam a base da regulação da governança das instituições financeiras no Brasil, em especial os regimes de responsabilização dos administradores e a estrutura de fiscalização e regulação à qual as instituições financeiras estão submetidas. Este primeiro momento compreende as décadas de 1960 e 1970.

O Momento II, também denominado "saneamento e privatização", corresponde às décadas de 80 e 90. Ele é marcado pelo fortalecimento institucional do BCB como condutor efetivo da politica monetária e da supervisão bancária em um cenário de forte inflação, agravamento de problemas fiscais e crises econômico-financeiras dos bancos estaduais. $\mathrm{O}$ saneamento do sistema financeiro compreende as medidas tomadas por meio de leis e regulações do $\mathrm{CMN}$ e do $\mathrm{BCB}$ com vistas ao aperfeiçoamento da governança corporativa das instituições financeiras e ao aumento da rigidez da responsabilidade dos controladores e dos poderes do BCB para imposição de medidas de recomposição patrimonial, alienações de controle e reestruturações societárias. Destacam-se o Decreto-Lei ${ }^{\circ} 2.321$, de 25 de 
fevereiro de 1987, que instituiu o Regime Especial de Administração Temporária (RAET) e a Lei no 9.447, de 14 de março de 1997.

Após a estabilização inflacionária e a exposição da má-governança de diversas instituições financeiras, um conjunto de medidas de saneamento foram tomadas para livrar o Sistema Financeiro Nacional de instituições mal geridas e torná-lo mais concentrado em instituições mais hígidas. Os exemplos mais ilustrativos neste sentido são as políticas públicas consubstanciadas no Programa de Estímulo à Reestruturação e ao Fortalecimento do Sistema Financeiro Nacional (PROER), Programa de Incentivo à Redução do Setor Público Estadual na Atividade Bancária (PROES) e do Programa de Fortalecimento das Instituições Financeiras Federais (PROEF). Neste segundo momento, o modelo brasileiro de governança corporativa de instituições financeiras sofreu modificações estruturais em decorrência das privatizações dos bancos estaduais, dada a sua relevância no setor. ${ }^{1}$

O Momento III, também denominado "internacionalização", compreende os anos 1990 e o início dos anos 2000. Esta época é marcada pelo impacto de normas internacionais, como as decorrentes de relatórios emitidos pelo Comitê de Supervisão Bancária da Basileia (BCBS, acrônimo em inglês de Basel Committee on Banking Supervision) e as de direito estrangeiro, na regulação da governança corporativa das instituições financeiras no Brasil. Este momento também é caracterizado por uma tentativa de recuperação do mercado de capitais brasileiro, com a criação do Novo Mercado (2001) e a promulgação da Lei $\mathrm{n}^{\circ} 10.303$, de 31 de outubro de 2001, que visou reformar a Lei $n^{\circ}$ 6.404, de 15 de dezembro de 1976, cujas normas de proteção aos acionistas minoritários haviam sido seriamente afetadas por mudanças feitas para viabilizar a maximização do prêmio de controle nas privatizações. ${ }^{2}$

Dentre os diversos fatores ligados a este fenômeno, destacam-se: (i) a ocorrência de crises econômicas com impactos internacionais, como as crises mexicana (1994), asiática (1997), russa (1998), bolha da internet (2000), a moratória argentina (2001), e a crise

\footnotetext{
1 "Em 1988, os bancos estaduais e as caixas econômicas estaduais respondiam por 10\% dos ativos e dos depósitos do sistema bancário, por $17 \%$ das operações de crédito e $6 \%$ do patrimônio líquido".SALVIANO JÚNIOR, Cleofas. Bancos Estaduais: dos problemas crônicos ao PROES. Brasília: Banco Central do Brasil, 2004. Disponível em: <http://www.bcb.gov.br/htms/public/BancosEstaduais/livro_bancos_estaduais.pdf>. Acesso em: 4 jan. 2017, pp. 18-19. Em 1996, os ativos das instituições financeiras estaduais correspondiam a $17 \%$ do sistema financeiro nacional, se levado em consideração seu valor contábil R\$ 123 bilhões. Em 1996 haviam 64 instituições financeiras estaduais. Ibid., p. 125. Atualmente há somente os bancos estaduais do Rio Grande do Sul, do Sergipe, do Espírito Santo, do Pará, de Brasília (distrital), e os bancos de desenvolvimento de Minas Gerais, do Espírito Santo.

${ }^{2}$ Destaca-se, neste caso, a Lei no 9.457, de 5 de maio de 1997, que eliminou diversos direitos dos acionistas minoritários, inclusive a oferta pública de aquisição de controle acionário constante do artigo 254 da Lei $\mathrm{n}^{\mathrm{o}}$ $6.404 / 1976$.
} 
financeira internacional (2008); (ii) a listagem de certificados de depósitos de valores mobiliários de instituições financeiras brasileiras na Bolsa de Valores de Nova York (NYSE), que as sujeita às normas da Securities and Exchange Commission (SEC) e da Lei Sarbannes-Oxley (SOX) e (iii) a atuação transnacional de instituições financeiras brasileiras, que as sujeitam a obrigações internacionais de combate à lavagem de dinheiro e financiamento do terrorismo (como o USA PATRIOT ACT, de 2001) e de fornecimento de informações a autoridades fiscais estrangeiras (como o FATCA, de 2010).

$\mathrm{O}$ Momento IV, de resposta às demandas tecnológicas e de mudanças valorativas, compreende os anos 2000 e a década de 2010 até o ano de 2016. A regulação da governança corporativa das instituições financeiras volta-se então a responder a demandas tecnológicas, como incorporar regras de proteção de dados pessoais dos clientes em um cenário de cada vez maior dependência de sistemas eletrônicos, a fim de cumprir com regras da Lei Complementar $\mathrm{n}^{\mathrm{o}}$ 105, de 10 de janeiro de 2001 (Lei do Sigilo Bancário) e da Lei $\mathrm{n}^{\circ}$ 12.965, de 23 de abril de 2014 (Marco Civil da Internet). Soma-se a isso a incorporação à governança das instituições financeiras brasileiras, de busca por novas soluções adotadas por empresas de serviços financeiros que fazem utilização intensiva de tecnologia através de investimentos em incubadoras ou concursos para a absorção de novas ideias a serem integradas em seus processos e produtos.

Este momento é caracterizado ainda pela busca de atendimento a valores da sociedade que passaram a adquirir protagonismo no debate da governança corporativa tão ou mais relevante do que a simples maximização dos dividendos dos acionistas. Estes valores estão associados a normas mais específicas de proteção dos direitos humanos e do meio-ambiente, bem como prevenção a atos de corrupção. Políticas de gestão de risco socioambiental, departamentos de compliance e controles internos, deixaram de ser grandes temas de debates acadêmicos e passaram a ser exigências legais e regulatórias, impactando toda a estrutura de governança das instituições financeiras brasileiras.

\subsection{Metodologia}

O presente trabalho não tem por objetivo estabelecer relações de causalidade, mas sim testar a hipótese dentro de uma construção histórica, em ordem cronológica, das reformas jurídicas em matéria de regulação da governança corporativa das instituições 
financeiras no Brasil. Para tanto, a metodologia de pesquisa utilizada consiste em revisão de literatura, periódicos e materiais oficiais.

Ressalta-se, contudo, que esta periodização dentro dos quatro momentos acima exposta é construída com base no momento de criação das normas que constituem a atual regulação da governança corporativa das instituições financeiras brasileiras. Isto não prejudica o fato de que, em momentos posteriores ao de sua criação, estas normas foram modificadas ou que tenha havido algum debate sobre elas.

O presente trabalho conta com o ano de 1964 como seu marco temporal inicial. Este foi o ano de promulgação da Lei $n^{\circ} 4.595$, que regula o Sistema Financeiro Nacional e cria o CMN e o BCB. A justificativa para a escolha deste ano é a de que não só o sistema de regulação e supervisão, como também a qualidade institucional do Banco Central e sua capacidade de fazer cumprir suas decisões (enforcement) impactam diretamente o modelo de governança corporativa adotado pelas instituições financeiras. ${ }^{3}$

O conceito de instituições financeiras utilizado neste trabalho é o de Eduardo Salomão Neto, com base na interpretação do art. 17 da Lei no $4.595 / 1964 .{ }^{4}$ Embora parte relevante das normas de regulação da governança corporativa, em especial as do CMN e do BCB sejam aplicáveis a diversas instituições, dentre elas, instituições financeiras e demais autorizadas a funcionar pelo $\mathrm{BCB}$, o foco do presente trabalho reside nas instituições financeiras e, por um critério de relevância, nos bancos comerciais que também têm registro de companhia aberta.

\footnotetext{
${ }^{3}$ Antes de 1964, os papeis de regulação do sistema financeiro brasileiro não eram muito claros e, a despeito de tentativas de criação de autoridades setoriais específicas para lidar com os problemas relativos ao crédito, como a Inspetoria-Geral dos Bancos em 1920 e da Superintendência da Moeda e do Crédito em 1945, na prática elas fracassaram devido ao poder econômico e político do Banco do Brasil, entidade detentora do monopólio da dívida pública, de emissões, do mercado de câmbio e da administração do tesouro nacional. Os monopólios do Banco do Brasil e sua proximidade com o poder político fizeram-no regulador de fato do sistema financeiro nacional. Neste mesmo sentido, ainda alguns autores identificam que o Banco Central somente pôde assumir de modo mais efetivo sua posição de autoridade após a extinção da conta-movimento no ano de 1986 . Cf. TAYLOR, Matthew. Institutional Development through Policy-Making: A Case Study of the Brazilian Central Bank. World Politics, [s.i], v. 61, n. 3, jun. 2009, p. 498. Disponível em: $<$ http://scholar.harvard.edu/files/levitsky/files/taylor_banco_central_brasil_2009.pdf $>$. Acesso em: 1 jan. 2017 Mais detalhes, no Capítulo 4, infra.

4 “"...] deve-se interpretar o artigo 17 da Lei $n^{\circ}$ 4.595/64, que define as instituições financeiras em função de suas atividades privativas, como exigindo cumulativamente, (i) a captação de recursos de terceiros em nome próprio, (ii) seguida de repasse financeiro através de operação de mútuo, (iii) com o intuito de auferir lucro derivado da maior remuneração dos recursos repassados com relação à dos recursos coletados, (v) desde que a captação seguida de repasse se realize em caráter habitual". (negrito no original). SALOMÃO NETO, Eduardo. Direito Bancário. 2. ed. São Paulo: Atlas, 2014, p. 38.
} 
Os bancos comerciais (ou carteiras comerciais de bancos múltiplos) aceitam depósitos e fornecem recursos para financiar o comércio, a indústria, as empresas prestadoras de serviços, as pessoas físicas e terceiros em geral. Portanto eles, não somente alcançam a maior parte da população, como são uma faceta mais visível e didática do conceito de instituição financeira como intermediação de depósitos e empréstimos, do que seriam outros tipos de instituição financeira, como sociedades de crédito, financiamento e investimento, sociedades de arrendamento mercantil, bancos de investimento ou bancos de desenvolvimento.

\subsection{Contribuição para a Literatura}

Espera-se que a presente monografia seja relevante para todos os que desejam compreender melhor, do ponto de vista histórico, como o Direito foi respondendo historicamente a determinadas pressões e moldando o exercício do poder no sistema financeiro brasileiro. ${ }^{5}$ Esta compreensão é essencial para o desenvolvimento de interpretações mais sofisticadas da regulação da governança corporativa. Além disso, visa contribuir com a literatura jurídica ao não se limitar à exposição do conteúdo das normas, mas também observar a conjuntura na qual elas foram sendo construídas.

\subsection{Estrutura}

Além da presente Introdução e da Conclusão, o trabalho está dividido em mais três partes. A primeira parte contém uma introdução teórica à governança corporativa das instituições financeiras. A segunda parte é composta por 6 capítulos, que tratam dos quatro principais momentos acima expostos. Em relação ao Momento I, o Capítulo 3 trata da modernização (e construção do atual) sistema financeiro brasileiro. No Momento II, o Capítulo 4 permitirá analisar a conjuntura do fortalecimento institucional do BCB e as crises dos bancos estaduais, e o Capítulo 5 descreverá como as políticas de saneamento do sistema financeiro para torna-lo mais hígido, bem como as privatizações impactaram a estrutura do

\footnotetext{
5 "Too often, the large firm's ownership structure is analyzed as a purely business institution, as one arising solely from organizational imperatives, technical foundations and financial needs. The political and social predicates that make the large firm possible and that shape its form are not scrutinized as carefully, or at all, despite that variation in political and social conditions can deeply affect which firms, which ownership structures, and which corporate governance arrangements survive and prosper". ROE, Mark. Political Determinants of Corporate Governance: Political Context, Corporate Impact. Nova York: Oxford University Press, 2011, p. v.
} 
setor bancário brasileiro e, consequentemente, a regulação da governança corporativa. $\mathrm{O}$ Momento III será descrito no Capitulo 6, que, dentro de um contexto de internacionalização da atividade bancária, examinará o impacto das normas internacionais e do direito estrangeiro na regulação da governança corporativa das instituições financeiras brasileiras. O Momento IV será descrito no Capítulo 7, que tratará de como as instituições financeiras devem incorporar em sua governança as preocupações relativas às demandas tecnológicas e expectativas sociais.

A terceira parte visa ilustrar o estágio atual da governança corporativa das instituições financeiras no Brasil, ao dissecar as estruturas de controle e administração e tratar brevemente das principais políticas de governança dos quatro maiores bancos comerciais do país (Bradesco, Banco do Brasil, Santander Brasil e Itaú Unibanco (Holding). A escolha destes bancos obedece a um critério de relevância com base nos dados de concentração de mercado do país. ${ }^{6}$ Por fim, segue a conclusão.

\footnotetext{
${ }^{6}$ Conforme os dados mais recentes publicados pelo Banco Central, as maiores instituições financeiras por valor de ativos são, respectivamente: Banco do Brasil, Itaú Unibanco, Caixa Econômica Federal, Bradesco e Santander Brasil, que representam $80 \%$ do valor dos ativos totais, $82 \%$ dos depósitos totais e $65 \%$ do patrimônio líquido dos bancos brasileiros, com a exclusão dos BNDES. Dados extraídos do Sistema IF Data, do Banco Central, data-base: setembro de 2016. BANCO CENTRAL DO BRASIL. Dados Selecionados de Entidades Supervisionadas - IF.data. Disponível em: <https://www3.bcb.gov.br/informes/relatorios $>$. Acesso em: 1 jan. 2017. O cálculo inclui bancos comerciais, múltiplos, com ou sem carteira comercial e caixa econômica, exclui cooperativas centrais e cooperações de crédito, bancos de desenvolvimento, cooperativas de crédito singulares, crédito não bancário e crédito via Mercado de capitais.
} 
mais relevantes pudesse refletir as transformações pelas quais o modelo brasileiro passou em decorrência da conjuntura característica da periodização empreendida no presente trabalho. Como visto, Bradesco e Itaú (Unibanco) se expandiram significativamente ao longo do Momento I. A atual dimensão do Santander Brasil é fruto da internacionalização do mercado bancário brasileiro, das privatizações (no caso, do Banespa) e da concentração do Sistema Financeiro Nacional, características dos Momentos II e III. Em relação ao ao atual momento, designado Momento IV, percebe-se no presente capítulo a adoção cada vez maior de um modelo de construção de imagem que vise responder à inovação tecnológica e, sobretudo, às demandas sociais, dado o destaque dado a adotado a políticas de sustentabilidade, proteção ao consumidor e compliance.

\section{Conclusões}

O presente trabalho buscou descrever a história contemporânea das instituições financeiras no Brasil do ponto de vista jurídico. Com isso, buscou-se estabelecer uma evolução temporal do arcabouço jurídico aplicável às instituições financeiras brasileiras a partir da Lei $\mathrm{n}^{\circ} 4.595 / 1964$, que forneceu a principal moldura jurídica do Sistema Financeiro Nacional, e buscou percorrer todo o período até hoje com base nas principais ferramentas normativas aplicáveis à governança corporativas instituições financeiras do país.

Se é possível falar em modelo brasileiro de governança corporativa das instituições financeiras, é certo que o arcabouço jurídico denominado neste trabalho "regulação da governança corporativa", sempre buscou responder a necessidades conjunturais da economia e dos valores da sociedade brasileira. A hipótese de que, em linhas gerais, a construção da regulação da governança corporativa contemporânea das instituições financeiras pode ser objeto de periodização em 4 grandes momentos históricos foi confirmada ao longo do presente trabalho. Com algumas exceções, o surgimento de normas que regularam a governança corporativa sempre obedeceu a conjunturas históricas muito bem definidas, que foram agrupadas ao longo deste trabalho.

Em relação ao Momento I, a mudança de governo em 1964 dentro de um contexto econômico de grave inflação, deu um impulso maior para que o governo autoritário (até então visto como provisório) buscasse modernizar o arcabouço jurídico da economia para conseguir alguma legitimidade popular. Não somente o PAEG no início do governo militar, como o Plano Trienal já contemplavam a necessidade de se modernizar o sistema financeiro 
brasileiro como uma forma de promover o desenvolvimento e o combate à inflação. A aprovação da Lei no 4.595/1964, que já estava em tramitação, das Leis de Mercado de Capitais (Lei $n^{\circ} 4.728 / 1965$, e, posteriormente, Lei $n^{\circ}$ 6.385/1976), do Decreto-Lei $n^{\circ}$ 157/1967 (com a concessão dos incentivos fiscais para investimento em ações), Lei dos Regimes Especiais das Instituições Financeiras (Lei n ${ }^{\circ}$ 6.025/1974) e Lei das Sociedades por Ações (Lei n ${ }^{\circ}$ 6.404/1976) ilustram bem este contexto.

No Momento II, o fim do milagre econômico e o aparecimento da hiperinflação tornaram expostos alguns dos problemas estruturais da economia brasileira, como elevada vulnerabilidade a endividamento externo, que sofreu significativo aumento com as crises do petróleo, a ruptura com o sistema de Bretton Woods decorrente da desvinculação do dólar ao padrão-ouro, o aumento de juros pelo Federal Reserve em 1973 e os problemas de gestão da dívida pública. No que tange a este último ponto, a forma federativa de Estado agravou o problema, na medida em que o próprio setor bancário público estadual, objeto de análise do presente trabalho, foi utilizado como instrumento de emissão de numerário, o que agravou o problema da inflação. As instituições financeiras estaduais, importantes ferramentas de política pública passaram a ser vistas pelo Governo Federal como um problema, pois suscitavam vez após vez pacotes de socorro financeiro do BCB.

Não só as instituições financeiras públicas estaduais sofreram problemas ao longo do Momento II. A estabilização econômica fez com que as instituições financeiras privadas perdessem o lucro fácil decorrente do floating inflacionário. Esta perda de receita criou problemas econômicos que, por sua vez, expuseram diversos problemas contábeis e fraudes, como concessão de créditos com inobservância da boa técnica bancária, falta de provisões para perdas e rolagem constante de empréstimos. Grandes bancos privados brasileiros, como Nacional, Bamerindus e Econômico, bem como os bancos estaduais, com destaque para Banespa e Banerj, foram grandes protagonistas deste momento.

É por isso que o Momento II ficou caracterizado, em matéria de regulação da governança corporativa, como um momento de saneamento do sistema financeiro e privatizações. Esta conjuntura permitiu que o BCB impusesse uma melhora de governança pela adoção de boas práticas bancárias em troca de suas linhas de assistência financeira, no âmbito do PROES e do PROER. O Decreto-Lei nº 2.321/1987 passou a tornar o controlador pessoalmente responsável pelas obrigações das instituições financeiras no caso de decretação do RAET, estendendo-se tal hipótese aos demais casos de decretação de regimes especiais e falência em virtude do advento da Lei $n^{\circ}$ 9.447/1997. Estas medidas jurídicas, 
além de visar o aperfeiçoamento da governança das instituições financeiras também prepararam terreno para a concentração do setor e para as privatizações das instituições financeiras estaduais.

A abertura de mercado nos anos 1990, a expansão internacional das instituições financeiras brasileiras, e os movimentos de globalização que difundiram globalmente boas práticas de governança corporativa e a busca pela uniformização de padrões regulatórios pelas diversas jurisdições também fizeram com que uma agenda de regulação internacional se impusesse sobre o sistema financeiro do Brasil. Acordos da Basileia, Novo Mercado, listagem de bancos brasileiros em bolsas de valores estrangeiras e guias de boas práticas de governança corporativa inspirados em discussões internacionais sobre o tema, contribuíram fortemente para moldar a atual governança corporativa nas instituições financeiras. A internacionalização do direito da governança corporativa atuou de maneira enérgica no fim da década de 1990 e na década de 2000, no que denominamos aqui de Momento III. Somase a isso a influência significativa do direito norte-americano nas práticas de governança e de gestão bancária das instituições financeiras brasileiras, como pelo FCPA, FATCA, SOX e USA PATRIOT ACT.

As discussões do atual momento (Momento IV) estão centradas nas respostas às demandas sociais em um contexto de novas atribuições de prioridades a valores e expectativas sociais. O surgimento dos debates sobre governança corporativa chamou a atenção sobretudo dos teóricos de linha marxiana de estudiosos da financeirização do capitalismo, como Robert Boyer. ${ }^{461}$ No dizer de Chesnais, a governança corporativa passaria

${ }^{461}$ BOYER, Robert. The Political in the Era of Globalization and Finance: Focus on Some Regulation School Research. International Journal Of Urban And Regional Research, [s.1.], v. 24, n. 2, p.274-322, jun. 2000. Wiley-Blackwell. http://dx.doi.org/10.1111/1468-2427.00250, p. 311. Robert Boyer também vislumbra a governança corporativa e sua normatização por meio da promoção do conceito de maximização do valor das ações como modo de regulação para endereçar as contradições de um regime de acumulação próprio de uma economia com dominância financeira. Esta é a denominada "Teoria da Regulação" (régulation theory). Conforme Robert Boyer, um de seus expoentes, este campo do pensando econômico se interessa em reestruturar as relações entre as esferas política e econômica por reconhecer as interações variadas em funcionamento nas sociedades contemporâneas, o que conduz a compromissos institucionais e novas formas de regulação ("régulation") que buscam responder a novos regimes de acumulação, sendo o direito uma delas. Contudo, é importante fazer uma observação linguística em relação ao uso do termo "régulation" por referida escola de pensamento econômico: "In British and American texts, written in English, the French term régulation is confused with 'regulation' (réglementation in French); furthermore, as a result of conservative deregulation strategies, English usage of the term 'regulation' has experienced a revival. However, régulation theory is not concerned with this area of investigation at all. While régulation theory originated in France, it was subsequently enriched by studies of many other countries, and was then faced with a major difficulty in the translation of its founding concept. In the words of Michel Aglietta, one of the founding fathers of régulation theory, it involves 'the analysis of the way in which transformations of social relations create new economic and non-economic forms, organised in structures that reproduce a determining structure, the mode 
a ser característica de nova categoria de capitalista financeiro, ou de rentista ativo, e estava associada a uma aumento da exploração do trabalho pelo capital. ${ }^{462}$ as expectativas sociais e suas respostas jurídicas fizeram com que, no presente momento, se superasse a visão da governança corporativa das instituições financeiras, com foco exclusivo na maximização do valor das ações. Cabe então à regulação da governança corporativa conciliar de alguma forma os interesses envolvidos, seja por meio de incentivos, seja por meio de sanções.

Esta priorização de valores não necessariamente econômicos fez perder um pouco o sentido exclusivo da governança corporativa como ferramenta de maximização de valor para o acionista. Por exemplo, mecanismos de governança socioambiental se tornaram exigência regulatória com a Resolução CMN no 4.327/2014. Somam-se a estas demandas sociais, os desafios tecnológicos que evidenciaram um papel mais ativo das áreas de controles de riscos operacionais, como proteção e gestão de dados, continuidade de negócios em situações de contingências e o uso cada vez maior da internet para a realização de operações, o que tem possibilitado o surgimento de novos negócios. Os escândalos de corrupção no Brasil e as repercussões sociais deles decorrentes também contribuíram para o aperfeiçoamento de políticas de prevenção a atos ilícitos e lavagem de dinheiro nas instituições financeiras.

Além da reconstrução histórica, o presente trabalho demonstrou que o atual sistema jurídico deve vislumbrar uma governança corporativa não mais tão oposta à regulação estatal, mas moldada por ela, e que não se preocupa exclusivamente com os interesses dos acionistas ou simplesmente em endereçar o conflito entre propriedade e controle. Em especial no caso dos bancos, nos quais os maiores provedores de recursos são os depositantes, a regulação do sistema financeiro visa assegurar que a governança corporativa resguarde seus interesses, muitas vezes à frente dos interesses dos acionistas, como bem ilustram as regras de responsabilidade ilimitada e a Resolução CMN nº 4.193/2013 em caso de descumprimento das regras prudenciais de Basileia III.

Como já afirmado no primeiro capítulo do presente trabalho, é evidente que este agrupamento histórico não corresponde a períodos absolutamente estanques. A divisão teve

of production”. BOYER, Robert. Introduction. In: BOYER, Robert; SAILLARD, Yves. Régulation Theory: The state of the art. Londres, Nova York: Routledge, 2002. Pp. 1-2.

${ }^{462}$ A governança corporativa está, segundo Chesnais, associada a adoção pelos dirigentes das empresas, dos elementos constitutivos da nova relação salarial, como mudanças organizacionais indispensáveis para a introdução das tecnologias portadoras de uma taxa de exploração aumentada". CHESNAIS, François. A teoria do regime de acumulação financeirizado: conteúdo, alcance e interrogações. Economia e Sociedade, Campinas, $\quad$ v. $11, \quad$ n. 1, p.1-44, jan./jun. 2002. Disponível em: <http://www.puro.uff.br/sites/default/files/user52/01-Chesnais financeirização.pdf>. Acesso em: 1 jan. 2017, p. 9 . 
por objetivo agrupar as reformas ou inovações jurídicas de forma cronológica, de acordo com as principais demandas características de cada momento da história, de modo a demonstrar como cada elemento do que podemos denominar de "modelo brasileiro de governança corporativa das instituições financeiras", foi sendo construído ao longo dos anos.

Visto que a história é uma obra que nunca termina, a realidade está sempre em mutação e o direito, em especial a estabilidade do direito econômico, muitas vezes depende de determinados arranjos políticos contingentes, acredita-se que a utilidade deste trabalho consiste na sistematização inédita, contextualizada historicamente, da regulação da governança corporativa das instituições financeiras e de suas práticas.

A abordagem aqui não é nova. A literatura da escola de pensamento denominada "Varieties of Capitalism" tem incorporado o estudo comparado da governança corporativa como um elemento importante para a compreensão do desenvolvimento econômico e social de diversos países, tanto desenvolvidos como subdesenvolvidos, com a utilização dos conceitos de economia de mercado liberais, coordenadas ou hierárquicas. ${ }^{463}$ Contudo, seu foco tem sido o sistema produtivo, ou a "economia real", ou o financiamento desta economia, mas sem foco nas instituições financeiras propriamente ditas. Neste sentido, o presente trabalho se distancia desta vertente.

Conforme já mencionado no capítulo introdutório, a presente pesquisa visa alcançar algum objetivo. Neste caso, o objetivo é dúplice: espera-se que seja significativo dentro de uma agenda de pesquisa em Direito Comercial e Econômico, que enxergue o arcabouço jurídico não só como contextualizado dentro de uma determinada realidade, fato já óbvio, mas que busque expor como e em que medida esta contextualização ocorre. O segundo é permitir ao intérprete do Direito, teórico ou prático, o desenvolvimento de técnicas mais sofisticadas de interpretação que levem a um resultado decisório mais adequado, ou legítimo.

${ }^{463}$ HALL, Peter A.; SOSKICE, David. An Introduction to Varieties of Capitalism. In: HALL, Peter A.; SOSKICE, David. Varieties of Capitalism: The institutional foundations of comparative advantage. Oxford: Oxford University Press, 2001, p 8, 9; 14-17; SCHNEIDER, Ben Ross. Hierarchical Capitalism in Latin America: Business, Labor, and the Challenges of Equitable Development. New York: Cambridge University Press, 2013, pp. 10, 12 e 13, 139-159. 


\section{BIBLIOGRAFIA}

ADJIEV, Stefan; KARTASHEVA, Anastasia; BOGDANOVA, Bilyana. CoCos: a primer. BIS Quarterly Review, Basileia, v. 0, n. 0, p.43-56, set. 2013. Disponível em: $<$ http://www.bis.org/publ/qtrpdf/r_qt1309f.pdf $>$. Acesso em: 3 jan. 2017.

ADMATI, Adnat; HELLWIG, Martin. The Bankers' New Clothes: What's Wrong with Banking and What to Do about It. Princeton: Princeton University Press, 2013.

ARCOVERDE, Letícia. Companhias desenvolvem áreas de compliance. Valor Econômico. São Paulo, p. 0-0. 9 jun. 2016. Disponível em: $<$ http://www.valor.com.br/carreira/4594353/companhias-desenvolvem-areas-decompliance>. Acesso em: 5 jan. 2017.

ASSOCIAÇÃO BRASILEIRA DE BANCOS. Cartilha de Governança Corporativa: Fortalecendo a Política de Governança nas Instituições Financeiras de Pequeno e Médio Porte. [s.1]: ABBC, 2009. Disponível em: $<$ http://www.abbc.org.br/ADM/publicacoesconfig/uploads/30333550179494052001_ABB C_Cartilha_Governanca_Corporativa.pdf>. Acesso em: 5 jan. 2017.

ASSOCIAÇÃO BRASILEIRA DE BANCOS INTERNACIONAIS E FEDERAÇÃO BRASILEIRA DE BANCOS. Função de Compliance. São Paulo: Febraban, [2011]. Disponível em: $<$ http://www.febraban.org.br/7rof7swg6qmyvwjcfwf7i0asdf9jyv/sitefebraban/funcoescom pliance.pdf>. Acesso em: 5 jan. 2017.

AYRES, Marcela. Briga de novela pôs herdeiras do Bradesco na lista da Forbes. Veja. [s.1.], 8 mar. 2012. Disponível em: <http://veja.abril.com.br/economia/briga-de-novela-posherdeiras-do-bradesco-na-lista-da-forbes/>. Acesso em: 1 maio 2017.

. Chamada no 3 - Programa InovaBRA Startups. Regulamento. Disponível em: $<$ https://wspj.bradescopessoajuridica.com.br/InovaBra/Site/_files/Regulamento.pdf $>$. Acesso em: 5 jan. 2017 
$<$ http://www.bradescori.com.br/site/conteudo/interna/default3.aspx? secaold=569 $>$. Acesso em: 5 jan. 2017.

Histórico de Aquisições. Disponível

em:

$<$ https://www.bradescori.com.br/site/conteudo/visao/historico-

aquisicoes.aspx?secaold=777>. Acesso em: 5 jan. 2017.

. Norma de Engajamento de Partes Interessadas. [s.1]: Bradesco, [2016].

Disponível

em:

$<$ https://www.bradescosustentabilidade.com.br/manager/uploads/file/Norma

de

Engajamento de Partes Interessadas.pdf>. Acesso em: 5 jan. 2017.

Relatório Anual. Osasco: Bradesco, 1965. Acervo do Museu Histórico Bradesco Fundação Bradesco.

. Relatório Anual. Osasco: Bradesco, 1966. Acervo do Museu Histórico Bradesco Fundação Bradesco.

. Relatório Anual. Osasco: Bradesco, 1967. Acervo do Museu Histórico Bradesco Fundação Bradesco.

. Relatório Anual. Osasco: Bradesco, 1979. Acervo do Museu Histórico Bradesco Fundação Bradesco

. Relatório Anual. Osasco: Bradesco, 1982. Acervo do Museu Histórico Bradesco Fundação Bradesco.

. Relatório Integrado 2015. Osasco: Bradesco, 2016. Disponível em: $<$ https://www.bradescori.com.br/site/conteudo/informacoes-financeiras/relatoriosanuais.aspx?secaoId=811>. Acesso em: 5 jan. 2017. 
BANCO CENTRAL DO BRASIL. Caixa de Amortização. Disponível em: $<$ http://www.bcb.gov.br/pre/Historia/HistoriaBC/caixa_amortizacao.asp?idpai=HISTORIA >. Acesso em: 3 jan. 2017.

. Dados Selecionados de Entidades Supervisionadas - IF.data. Disponível em: $<$ https://www3.bcb.gov.br/informes/relatorios>. Acesso em: 1 jan. 2017.

. Empresas sob regime especial - Mapa geral por tipo/nome de empresa. Disponível em: $<$ http://www4.bcb.gov.br/Lid/Liquidacao/patual/relacao.asp?idpai=REGESP $>$. Acesso em: 5 jan. 2017.

História da SUMOC. Disponível em: $<$ http://www.bcb.gov.br/pre/Historia/Sumoc/historiaSumoc.asp>. Acesso em: 3 jan. 2017.

Quem é quem. Disponível em: $<$ http://www.bcb.gov.br/pre/quemequem/port/quemequem.asp>. Acesso em: 1 mar. 2017.

. Ranking de Instituições por Índice de Reclamações. Disponível em: $<$ http://www.bcb.gov.br/ranking/index.asp>. Acesso em: 5 jan. 2017.

Recomendações de Basiléia. Disponível em: $<$ https://www.bcb.gov.br/fis/supervisao/basileia.asp>. Acesso em: 5 jan. 2017.

BANCO DO BRASIL. Banco do Brasil instala Laboratório no Vale do Silício. 2016. Disponível em: <http://www.bb.com.br/pbb/pagina-inicial/imprensa/n/53743/banco-dobrasil-instala-laboratorio-no-vale-do-silicio\#/>. Acesso em: 5 jan. 2017.

. Estatuto Social. 2016. 28 de abril de 2016. Disponível em: $<$ http://www.bb.com.br/docs/pub/siteEsp/ri/pt/dce/dwn/EstatutoSocial.pdf>. Acesso em: 5 jan. 2017.

- Relatório Anual 2015. Brasília: Banco do Brasil, 2015. Disponível em: $<$ http://www.bb.com.br/docs/pub/siteEsp/uds/dwn/BBRA15.pdf>. Acesso em: 5 jan. 2017. 
BANCO SANTANDER (BRASIL) S.A. Composição Acionária. [2016]. Disponível em: $<$ https://www.ri.santander.com.br/show.aspx?idMateria=59d/zqZLtaULjbVROcCLrA==>. Acesso em: 5 jan. 2017.

\section{Estatuto}

Social. Disponível

em:

$<$ https://www.ri.santander.com.br/show.aspx?idMateria=EvaCCUsp4QwjMClHReBe9A= $=>$. Acesso em: 5 jan. 2017.

\section{Práticas}

de

Governança. Disponível

em:

$<$ https://www.ri.santander.com.br/show.aspx?idMateria=N55NYV9V5fqixNdzSMzigA== >. Acesso em: 5 jan. 2017.

. Relatório Anual 2015. São Paulo: Banco Santander (Brasil) S.A., 2016. Disponível em: $<$ https://sustentabilidade.santander.com.br/pt/Espaco-dePraticas/Paginas/NoticiaparadivulgacaodoRAnoPortaldeSustentabilidade.aspx $>$. Acesso em: 1 jan. 2017

\section{Santander no Brasil: História. [2016]. Disponível em:} $<$ https://www.santander.com.br/portal/wps/script/templates/GCMRequest.do?page=6413>. Acesso em: 5 jan. 2017.

BANK FOR INTERNATIONAL SETTLEMENTS. About the Basel Committee. 2016. Disponível em: <http://www.bis.org/bcbs/about.htm>. Acesso em: 5 jan. 2017

$$
\text { Basel Committee membership. 2016. Disponível em: }
$$
$<$ http://www.bis.org/bcbs/about.htm>. Acesso em: 5 jan. 2017

History of the Basel Committee. 2017. Disponível em: $<$ http://www.bis.org/bcbs/history.htm>. Acesso em: 3 jan. 2017. 
BARBOSA, Fernando de Holanda. O Sistema Financeiro Brasileiro. Fundação Getúlio Vargas. Disponível em: <http://www.fgv.br/professor/fholanda/Arquivo/Sistfin.pdf>. Acesso em: 1 mar. 2017.

\section{BASEL COMMITTEE ON BANKING SUPERVISION. Amendment to the Capital} Accord to Incorporate Market Risks. Basileia: Bank For International Settlements, 1996. Disponível em: <http://www.bis.org/publ/bcbs24.pdf>. Acesso em: 5 jan. 2017.

. Basel III: International framework for liquidity risk measurement, standards and monitoring. Basileia: Bank For International Settlements, 2010. Disponível em: $<$ http://www.bis.org/publ/bcbs188.pdf>. Acesso em: 4 jan. 2017.

Basel III: A global regulatory framework for more resilient banking systems. Basileia: Bank For International Settlements, 2010. Disponível em: $<$ http://www.bis.org/publ/bcbs189_dec2010.pdf>. Acesso em: 5 jan. 2017.

. Best Practices for Credit Disclosure. Basileia: Bank For International Settlements, 1999. Disponível em: < http://www.bis.org/publ/bcbs53.pdf>. Acesso em: 3 jan. 2017.

. Enhancing corporate governance for banking organisations. Basel: Bank For International Settlements, 1999. Disponível em: <https://www.bis.org/publ/bcbsc138.pdf $>$. Acesso em: 1 jan. 2017.

. Enhancing corporate governance for banking organizations. Basileia: Bank For International Settlements, 2006. Disponível em: <http://www.bis.org/publ/bcbs122.pdf>. Acesso em: 3 jan. 2017.

. Enhancing Public Transparency. Basileia: Bank For International Settlements, 1998. Disponível em: <http://www.bis.org/publ/bcbs41.pdf>. Acesso em: 3 jan. 2017.

- Guidelines: Corporate governance principles for banks. Basileia: Bank For International Settlements, 2015. Disponível em: <http://www.bis.org/bcbs/publ/d328.pdf>. Acesso em: 3 jan. 2017. 
- International Convergence of Capital Measurement and Capital

Standards. Basileia: Bank For International Settlements, 1998. Disponível em: $<$ http://www.bis.org/publ/bcbsc111.pdf>. Acesso em: 5 jan. 2017.

. International Convergence of Capital Measurement and Capital Standards: A

Revised Framework - Comprehensive Version. Basileia: Bank For International Settlements, 2004. Disponível em: <http://www.bis.org/publ/bcbs128.pdf>. Acesso em: 5 jan. 2017.

. Principles for Enhancing Corporate Governance. Basileia: Bank For International Settlements, 2010. Disponível em: <http://www.bis.org/publ/bcbs176.pdf $>$. Acesso em: 3 jan. 2017.

Principles for Management of Interest Risk. Basileia: Bank For International Settlements, 1997. Disponível em: <http://www.bis.org/publ/bcbs108.pdf>. Acesso em: 3 jan. 2017.

BLOOMBERG L.P. Company Overview of Sterrebeeck B.V. Disponível em: $<$ http://www.bloomberg.com/research/stocks/private/snapshot.asp?privcapId=73426497>. Acesso em: 5 jan. 2017.

BM\&FBOVESPA. Empresas Listadas por Setor de Atuação. Disponível em: $<$ http://bvmf.bmfbovespa.com.br/cias-listadas/empresaslistadas/BuscaEmpresaListada.aspx?segmento=Bancos\&idioma=pt-br $>$. Acesso em: 5 jan. 2017.

. Novo Mercado: Regulamento de Listagem, Regulamento de Aplicação de Sanções Pecuniárias, Cláusulas Mínimas Estatutárias. São Paulo: BM\&FBovespa, 2011.

- Segmentos de Listagem. Disponível em:

$<$ http://www.bmfbovespa.com.br/pt_br/listagem/acoes/segmentos-de-listagem/sobresegmentos-de-listagem/>. Acesso em: 5 jan. 2017. 
BOYER, Robert. The Political in the Era of Globalization and Finance: Focus on Some Regulation School Research. International Journal Of Urban And Regional Research, [s.1.], $\quad$ v. 24, n. 2, p.274-322, jun. 2000. Wiley-Blackwell. http://dx.doi.org/10.1111/1468-2427.00250, p. 311.

. Introduction. In: BOYER, Robert; SAILLARD, Yves. Régulation Theory: The state of the art. Londres, Nova York: Routledge, 2002.

BRAGA, Vicente Piccoli Medeiros. Arbitragem Regulatória X One Size Fits All: A discricionariedade na regulação bancária internacional entre Cíla e Caríbdis. 2014. 1 v. Dissertação (Mestrado) - Curso de Direito, Escola de Direito de São Paulo, Fundação Getúlio Vargas, São Paulo, 2014.

BRANDÃO, Ignácio de Loyola; OKUBARO, Jorge. Desvirando a Página: A Vida de Olavo Setúbal. São Paulo: Global, 2008.

BRASIL. ADVOCACIA GERAL DA UNIÃO. Parecer CGR SR-70. Brasília: AGU, 1988. Disponível em: <http://www.agu.gov.br/page/atos/detalhe/idato/7916>. Acesso em: 5 jan. 2017.

. Mensagem n ${ }^{0}$ 52-63 do Senhor Presidente da República João Goulart, de 23 de março de 1963. Diário do Congresso Nacional dos Estados Unidos do Brasil, Seção I. Brasília, 6 de abril de 1963.

. MINISTÉRIO DO PLANEJAMENTO E COORDENAÇÃO ECONÔMICA. Programa de Ação Econômica do Governo 1964-1966. Brasília: Ministério do Planejamento e Coordenação Econômica, 1965.

. PORTAL BRASIL. Banco do Brasil celebra 70 anos de atividades no exterior. 2011. Disponível em: <http:/www.brasil.gov.br/economia-eemprego/2011/12/banco-do-brasil-celebra-70-anos-de-atividades-no-exterior $>$. Acesso em: 5 jan. 2017. 


\section{PRESIDÊNCIA DA REPÚBLICA. Plano Trienal de Desenvolvimento}

Econômico e Social 1963-1965. Brasília: Presidência da República, 1962.

\section{. CÂMARA DOS DEPUTADOS. Relatório Final da Comissão Parlamentar de} Inquérito destinada a investigar as relações do Banco Central do Brasil com o Sistema Financeiro Privado. Brasília, 2002. Relator Deputado Alberto Goldman. Disponível em: $<$ http://www2.camara.leg.br/atividade-legislativa/comissoes/comissoestemporarias/parlamentar-de-inquerito/51-legislatura/cpiproer/relatoriofinal.html $>$. Acesso em: 4 jan. 2017.

- SENADO FEDERAL. CPI do Proer foi arquivada por falta de fato determinado. Jornal do Senado. Brasília, 6 jun. 2005. Disponível em: $<$ http://www12.senado.leg.br/jornal/edicoes/2005/06/06/cpi-do-proer-foi-arquivada-porfalta-de-fato-determinado>. Acesso em: 4 jan. 2017.

. Superior Tribunal de Justiça. Recurso Especial no 730617. Antônio Augusto de Almeida Leite e outros. Relator: Ministro Honildo Amaral de Mello Castro (Desembargador Convocado do TJ-AP). Brasília, DF, 28 de junho de 2011. Diário da Justiça Eletrônico. Brasília, 6 set. 2011.

. Supremo Tribunal Federal. Ação Direta de Inconstitucionalidade $n^{0} 4$. Requerente: Partido Democrático Trabalhista - PDT. Intimado: Presidente da República. Relator: Sydney Sanches. Brasília, DF, 7 de março de 1991. Diário da Justiça. Brasília, 25 jun. 1993.

- Supremo Tribunal Federal. Medida Cautelar na Ação Direta de Inconstitucionalidade $n^{\circ}$ 1315. Partido dos Trabalhadores. Relator: Ministro Ilmar Galvão. Brasília, 10 de agosto de 1995. Diário da Justiça. Brasília, 25 ago. 1995. v. 1797, n. 2, p. 293

CAPRIO JUNIOR, Gerard; LEVINE, Ross. Corporate Governance of Banks: Concepts and International Observations. [s.1]: World Bank, 2002. 
CHESNAIS, François. A teoria do regime de acumulação financeirizado: conteúdo, alcance e interrogações. Economia e Sociedade, Campinas, v. 11, n. 1, p.1-44, jan./jun. 2002. Disponível em: $\quad<$ http://www.puro.uff.br/sites/default/files/user52/01-Chesnais financeirização.pdf>. Acesso em: 1 jan. 2017.

CIANCANELli, Penny; REYES-GONZALEZ, Jose Antonio. Corporate Governance in Banking: A Conceptual Framework. SSRN Electronic Journal, [s.1.], p.1-28, jun. 2000. Elsevier BV. http://dx.doi.org/10.2139/ssrn.253714.

COELHO, João Ricardo. Os institutos da intervenção e da liquidação extrajudicial de instituições financeiras: a atuação do Banco Central e as "quebras" ocorridas entre 1974 e 1984. Revista de Ciência Política, Rio de Janeiro, v. 28, n. 3, p. 62-118, mar. 2016. ISSN 0034-8023.

Disponível em: $<$ http://bibliotecadigital.fgv.br/ojs/index.php/rcp/article/view/60243/58555>. Acesso em: 04 Jan. 2017.

COMPARATO, Fábio Konder; SALOMÃO FILHO, Calixto. O Poder de Controle na Sociedade Anônima. 6. ed. Rio de Janeiro: Forense, 2014.

COMMITTEE ON THE FINANCIAL ASPECTS OF CORPORATE GOVERNANCE. Report on the Committee on The Financial Aspects of Corporate Governance. Londres: Gee And Co Ltd., 1992. Disponível em: $<$ http://www.ecgi.org/codes/documents/cadbury.pdf>. Acesso em: 1 jan. 2017.

CONSELHO DA JUSTIÇA FEDERAL. Enunciados Aprovados - I Jornada de Direito Civil. Disponível em: <http://daleth.cjf.jus.br/revista/enunciados/IJornada.pdf $>$. Acesso em: 3 jan. 2017.

CONSELHO NACIONAL DE JUSTIÇA. 100 Maiores Litigantes. Brasília: Conselho Nacional de Justiça, 2011. Disponível em: <http://www.cnj.jus.br/images/pesquisasjudiciarias/pesquisa_100_maiores_litigantes.pdf $>$. Acesso em: 1 jan. 2017.

COSTA, Fernando Nogueira da. Brasil dos Bancos. São Paulo: Edusp, 2012. 
COSTA NETO, Yttrio Corrêa da. Bancos Oficiais no Brasil: Origem e Aspectos de seu Desenvolvimento. Brasília: Banco Central do Brasil, 2004. Disponível em: $<$ https://www.bcb.gov.br/htms/public/BancosEstaduais/livros_bancos_oficiais.pdf $>$. Acesso em: 3 jan. 2017.

DESIDÉRIO, Mariana. Conheça as fintechs, as startups que desafiam os bancos. Exame. São Paulo, 12 ago. 2016. Disponível em: $<$ http://exame.abril.com.br/pme/conheca-as-fintechs-as-startups-que-desafiam-osbancos/>. Acesso em: 5 jan. 2017.

DURAN-FERREIRA, Camila. O STF e a construção institucional das autoridades reguladoras do financeiro: um estudo de caso das ADIns. Revista Direito GV [s.1.], v. 5, n. 1, p.67-94, jun. 2009. FapUNIFESP (SciELO). http://dx.doi.org/10.1590/s180824322009000100004. Disponível em: <http://www.scielo.br/pdf/rdgv/v5n1/a04v5n1.pdf>. Acesso em: 3 jan. 2017.

THE ECONOMIST. Sarbanes Oxley: A price worth paying? The Economist. [s.1], p. 0-0. 19 maio 2005. Disponível em: <http://www.economist.com/node/3984019>. Acesso em: 5 jan. 2017.

EICHENGREEN, Barry. Globalizing Capital: A History of the International Monetary System. 2. ed. Princeton: Princeton University Press, 2008.

THE EQUATOR PRINCIPLES ASSOCIATION. About the Equator Principles. 2011. Disponível em: <http://www.equator-principles.com/index.php/about>. Acesso em: 5 jan. 2017.

. Equator Principles Association Members \& Reporting. 2011. Disponível em: $<$ http://www.equator-principles.com/index.php/members-reporting $>$. Acesso em: 5 jan. 2017.

. Os Princípios do Equador - Junho de 2013: Um referencial do setor financeiro para identificação, avaliação e gerenciamento de riscos socioambientais em projetos. [s.1]: The Equator Principles Association, 2013. Disponível em: <http://www.equator- 
principles.com/resources/equator_principles_portuguese_2013.pdf $>$. Acesso em: 5 jan. 2017.

ESTADOS UNIDOS DA AMÉRICA. DEPARTMENT OF JUSTICE. Foreign Corrupt

Practices Act: An Overview. Disponível em: <https://www.justice.gov/criminalfraud/foreign-corrupt-practices-act>. Acesso em: 5 jan. 2017.

. FINANCIAL CRISIS INQUIRY COMMISSION - UNITED STATES OF AMERICA. The Financial Crisis Inquiry Report: Final Report of the National Commission on the Causes of the Financial and Economic Crisis in the United States of America. Washington, D.C: Public Affairs Report, 2011. Disponível em: $<$ https://www.gpo.gov/fdsys/pkg/GPO-FCIC/pdf/GPO-FCIC.pdf $>$. Acesso em: 3 jan. 2017.

. Office of the Historian. Department of State. Nixon and the End of the Bretton

Woods System, 1971-1973. Disponível em: <https:/history.state.gov/milestones/19691976/nixon-shock>. Acesso em: 1 jan. 2017.

FAUSTO, Boris. História do Brasil. 14. ed. São Paulo: Edusp, 2015.

FERNANDES, Adriana; SOUZA, Nivaldo; PORTO, Gustavo. Governo nega boato sobre confisco da poupança O Estado de São Paulo. São Paulo, 13 fev. 2015. Disponível em: $<$ http://economia.estadao.com.br/noticias/geral,governo-nega-boato-sobre-confisco-dapoupanca, 1634070>. Acesso em: 5 jan. 2017.

FRANCO, Gustavo. O Banco Central desfigurado: anatomia do desastre, 1964-1993. Disponível em: <http://www.gustavofranco.com.br/uploads/files/Capítulo 6 - BCB o amadurecimento.pdf>. Acesso em: 3 jan. 2017.

FRANCO, Gustavo; ROSMAN, Luiz Alberto. A Responsabilidade Ilimitada em Instituições Financeiras no Brasil: Antecedentes, Experiência e Considerações. In: BOLLE, Monica Baumgarten de; CARNEIRO, Dionísio Dias. A Reforma do Sistema Financeiro Americano: Nova Arquitetura Internacional e o Contexto Regulatório Brasileiro. São Paulo: Ltc, 2010. p. 1-10. Disponível em: <http://www.economia.pucrio.br/gfranco/Regfin_G.Franco\&Rosman_cap7.pdf >. Acesso em: 1 jan. 2017. 
FUNDAÇÃO BRADESCO. História da Organização Bradesco. Disponível em: $<$ http://www.fundacaobradesco.org.br/museu/banco.asp>. Acesso em: 5 jan. 2017.

. Museu Histórico Bradesco. Osasco: Fundação Bradesco, n. 7, [2010]. Disponível em: <http://www.fundacaobradesco.org.br/museu/pdf/Revista do Museu - 7a Edição.pdf>. Acesso em: 5 jan. 2017, p. 35.

FUNDAÇÃO GETÚlIO VARGAS. VERBETE PROGRAMA DE ACAO ECONOMICA DO GOVERNO (PAEG). Centro de Pesquisa e Documentação de História Contemporânea do Brasil. Disponível em: $<$ http://www.fgv.br/cpdoc/acervo/dicionarios/verbete-tematico/programa-de-acaoeconomica-do-governo-paeg>. Acesso em: 3 jan. 2017.

GIAMBIAGI, Fabio; BARBOSA, Fabio. O ajuste fiscal de 1990-93: uma análise retrospectiva.Revista Brasileira de Economia, Rio de Janeiro, v. 49, n. 3, p. 521-544, jul. 1995. ISSN 0034-7140. Disponível em:

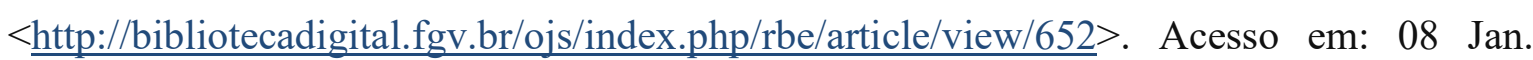
2017.

GILSON, Ronald J.; HANSMANN, Henry; PARGENDLER, Mariana. Regulatory Dualism as a Development Strategy: Corporate Reform in Brazil, the U.S., and the EU. SSRN Electronic Journal, [s.1.], p.1-54, mar. 2010. Elsevier BV. http://dx.doi.org/10.2139/ssrn.1541226.

GORGA, Érica. Direito Societário Atual. Rio de Janeiro: Elsevier, 2013.

HALL, Peter A.; SOSKICE, David. An Introduction to Varieties of Capitalism. In: HALL, Peter A.; SOSKICE, David. Varieties of Capitalism: The institutional foundations of comparative advantage. Oxford: Oxford University Press, 2001 
HAU, Harald; THUM, Marcel. Subprime crisis and board (in-) competence: private versus public banks in Germany. Economic Policy, [s.1.], v. 24, n. 60, p.701-752, out. 2009. Oxford University Press (OUP). http://dx.doi.org/10.1111/j.1468-0327.2009.00232.x.

HOPT, Klaus. Better Governance of Financial Institutions. ECGI Working Paper Series In Law, [s.i], v. $0, \quad$ n. 207, p.1-65, abr. 2013. Disponível em: $<$ https://papers.ssrn.com/sol3/papers.cfm?abstract_id=2212198>. Acesso em: 2 jan. 2017.

INSTITUTO BRASILEIRO DE GOVERNANÇA CORPORATIVA. Código das Melhores Práticas de Governança Corporativa. 5. ed. São Paulo: IBGC, 2015. Disponível em: <http://www.ibgc.org.br/userfiles/2014/files/CMPGPT.pdf>. Acesso em: 2 jan. 2017.

INSTITUTO PAULO MONTENEGRO - AÇÃO EDUCATIVA. Indicador de Analfabetismo Funcional: Estudo especial sobre analfabetismo e mundo do trabalho. São Paulo: Instituto Paulo Montenegro, 2016. Disponível em: <http://acaoeducativa.org.br/wpcontent/uploads/2016/09/INAFEstudosEspeciais_2016_Letramento_e_Mundo_do_Trabalh o.pdf>. Acesso em: 5 jan. 2017.

ITAÚ UNIBANCO. Ações Itaú em Foco: Informativo para Acionistas. 2016. Ano 13 - $2^{\text {o }}$ trimestre 2016.2 Disponível em: $<$ https://www.itau.com.br/_arquivosestaticos/RI/pdf/pt/Itau_em_Foco_2T16.pdf?title=Açõ es Itaú em Foco\%>. Acesso em: 5 jan. 2017.

ITAÚ UNIBANCO HOLDING S.A. Compromisso com os Direitos Humanos. [s.1]: Itaú Unibanco, [2016]. Disponível em: $<$ https://www.itau.com.br/_arquivosestaticos/Itau/PDF/Sustentabilidade/Compromisso_Ita u_com_Direitos_Humanos_Port.pdf $>$. Acesso em: 5 jan. 2017, p. 1.

Estatuto Social. Disponível em: $<$ https://www.itau.com.br/_arquivosestaticos/RI/pdf/pt/Estatuto_Portugues.pdf?title=Estat uto Social>. Acesso em: 5 jan. 2017. 
$<$ http://www.itauunibanco.com.br/relatoriodesustentabilidade/pt-br/historia/ $>$. Acesso em: 5 jan. 2017

. Política Corporativa de Prevenção à Corrupção. São Paulo: Itaú Unibanco, 2016. Disponível em: $<$ https://www.itau.com.br/_arquivosestaticos/RI/pdf/pt/POLITICA_CORPORATIVA_DE _PREVENCAO_A_CORRUPCAO_PORT.pdf?title=Política Corporativa de Prevenção à Corrupção>. Acesso em: 5 jan. 2017.

. Relatório Anual Consolidado 2015. São Paulo: Itaú Unibanco, 2016. Disponível em: <https://www.itau.com.br/_arquivosestaticos/RI/pdf/pt/Itau_RAC_2015_port.pdf>. Acesso em: 5 jan. 2017.

. Relatório Integrado 2015. São Paulo: Itaú Unibanco, 2016. Disponível em: $<$ https://www.itau.com.br/_arquivosestaticos/RI/pdf/pt/Relato_Integrado_2015.pdf?title=R elato Integrado2015>. Acesso em: 1 jan. 2017, p. 16.

. Shareholders' Agreement of IUPAR - Itaú Unibanco Participações S.A., and of Itaú Unibanco Banco Múltiplo S.A., firmado entre Fernando Roberto Moreira Salles, Walther Moreira Salles Júnior, Pedro Moreira Salles, João Moreira Salles, Itaúsa - Investimentos Itaú S.A., IUPAR - Itaú Unibanco Participações S.A., Itaú Unibanco Banco Múltiplo S.A., Banco Itaú S.A., e Unibanco - União de Bancos Brasileiros S.A., de 27 de janeiro de 2009.2009. Disponível em: $<$ https://www.itau.com.br/_arquivosestaticos/RI/pdf/IUPARingles.pdf $>$. Acesso em: 5 jan. 2017.

ITAÚSA - INVESTIMENTOS ITAÚ S.A. Acordo de Acionistas da Itaúsa Investimentos Itaú S.A., de 01/09/2015.2015. Disponível em: $<$ http://static.itausa.mediagroup.com.br/Imagens/acordo_acionistas_01092015.pdf $>$. Acesso em: 5 jan. 2017. 
KAY, John. Other People's Money: The Real Business of Finance. Nova York: Public Affairs, 2015.

LEGAL INFORMATION INSTITUTE - CORNELL UNIVERSITY LAW SCHOOL. 15 U.S. Code $§ 7241$ - Corporate responsibility for financial reports. 2010. Disponível em: $<$ https://www.law.cornell.edu/uscode/text/15/7241>. Acesso em: 5 jan. 2017.

15 U.S. Code $§ 7264$ - Code of ethics for senior financial officers. 2010. Disponível em: <https://www.law.cornell.edu/uscode/text/15/7264>. Acesso em: 5 jan. 2017.

15 U.S. Code $§ 781$ - Registration requirements for securities. 2010. Disponível em: <https://www.law.cornell.edu/uscode/text/15/781>. Acesso em: 5 jan. 2017.

15 U.S. Code $\S \mathbf{7 8 j - 1}$ - Audit requirements. 2010. Disponível em: $<$ https://www.law.cornell.edu/uscode/text/15/78j-1>. Acesso em: 5 jan. 2017.

26 U.S. Code $\S 1471$ - Withholdable payments to foreign financial institutions. 2010. Disponível em: <https://www.law.cornell.edu/uscode/text/26/1471>. Acesso em: 5 jan. 2017.

MACEY, Johnathan; O'HARA, Maureen. Bank Corporate Governance: A Proposal for the Post-Crisis World. FRBNY Economic Policy Review, Nova York, v. 22, n. 1, p.85-105, ago. 2016.2 Disponível em: $<$ https://www.newyorkfed.org/medialibrary/media/research/epr/2016/epr_2016_postcrisis-world_macey.pdf?la=en>. Acesso em: 2 jan. 2017.

MARQUES, Felipe. Banco privado retoma apetite por linhas do BNDES. Valor Econômico. São Paulo, 29 maio 2014. Disponível em: $<$ http://www.valor.com.br/financas/3566896/banco-privado-retoma-apetite-por-linhas-dobndes>. Acesso em: 3 jan. 2017. 
MORAES, Maurício. Pioneiro na informatização, Itaú cultiva imagem de banco inovador e moderno. Folha de São Paulo. São Paulo, 4 nov. 2008. Disponível em: $<$ http://www1.folha.uol.com.br/fsp/dinheiro/fi0411200824.htm>. Acesso em: 5 jan. 2017.

NABUCO, Joaquim. Um Estadista do Império: Nabuco de Araújo. São Paulo: Instituto Progresso Editorial, 1949. 2 v.

NASSIF, Luis. Manual de Maquilagem Bancária. Folha de São Paulo. São Paulo, 21 ago. 1996. Disponível em: <http://www1.folha.uol.com.br/fsp/1996/8/21/dinheiro/6.html>. Acesso em: 5 jan. 2017

NENOVA, Tatiana. Control Values and Changes in Corporate Law in Brazil. Latin American Business Review, [s.1.], v. 6, n. 3, p.1-37, 7 mar. 2006. Informa UK Limited. http://dx.doi.org/10.1300/j140v06n03 01.

NESTOR ADVISORS LTD. Bank Boards and the Financial Crisis: A corporate governance study of the 25 largest European banks. Londres: Nestor Advisors Ltd, 2009.

NEW YORK STOCK EXCHANGE. Current List of All Non-U.S. Issuers. 2016. Disponível em: <https://www.nyse.com/publicdocs/nyse/data/CurListofallStocks.pdf>. Acesso em: 5 jan. 2017.

NÓBREGA, Mailson da. O Poder do Ministro da Fazenda. Folha de São Paulo. São Paulo, 11 jun. $1999 . \quad$ Disponível em: <http://www1.folha.uol.com.br/fsp/dinheiro/fi11069906.htm>. Acesso em: 4 jan. 2017.

ONARAN, Yalman. Bloomberg L.P. Capital Requirements: Limiting Bank Leverage. 2016. Disponível em: <https://www.bloomberg.com/quicktake/banks-leverage-capitalratios>. Acesso em: 2 jan. 2017.

ORGANIZAÇÃO DAS NAÇÕES UNIDAS. Empresas e Direitos Humanos: Parâmetros da ONU para Proteger, Respeitar e Reparar. São Paulo: Conectas Direitos Humanos, 2012. Relatório Final de John Ruggie - Representante do Secretário-Geral. Disponível em: 
$<\mathrm{http}$ ://www.conectas.org/arquivos-

site/Conectas_PrincípiosOrientadoresRuggie_mar2012(1).pdf>. Acesso em: 5 jan. 2017.

ORGANIZAÇÃO PARA COOPERAÇÃO E DESENVOLVIMENTO ECONÔMICO. Corporate Governance and the Financial Crisis: Key Findings and Main Messages. [s.1]: $2009 . \quad$ OECD, Disponível em: $<$ http://www.oecd.org/corporate/ca/corporategovernanceprinciples/43056196.pdf $>$. Acesso em: 2 jan. 2017.

.. OECD Principles of Corporate Governance. [s.1]: OCDE, 1999. Disponível em: $<$ http://www.oecd.org/officialdocuments/publicdisplaydocumentpdf/?cote=C/MIN(99)6\&d ocLanguage $=$ En $>$. Acesso em: 5 jan. 2017.

PARGENDLER, Mariana. Evolução do Direito Societário: Lições do Brasil. São Paulo: Saraiva, 2013.

. The Corporate Governance Obsession. Journal of Corporation Law, vol. 42, n. 2, 2016, pp. 101-144.

. State Ownership and Corporate Governance. Fordham Law Review, [s.1.], v. 80, n. 6, p.2917-2973, maio 2012. Elsevier BV. http://dx.doi.org/10.2139/ssrn.185445, pp. 2935-2936.

PEDRAS, Guilherme Binato Vilella. História da Dívida Pública no Brasil: de 1964 até os dias atuais. In: SILVA, Anderson Caputo; CARVALHO, Lena Oliveira de; MEDEIROS, Otavio Ladeira de (Org.). Dívida Pública: A experiência brasileira. Brasília: Secretaria do Tesouro Nacional, 2009. p. 57-80. Disponível em: $<$ http://www3.tesouro.gov.br/divida_publica/downloads/livro/livro_eletronico_completo.p df $>$. Acesso em: 5 jan. 2017

POSER, Norman S. Securities Regulation in Developing Countries: The Brazilian Experience. Virginia Law Review, [s.1.], v. 52, n. 7, p.1283-1307, nov. 1966. JSTOR. http://dx.doi.org/10.2307/1071450. 
PRATES, Daniela Magalhães. Bancos e ciclo de crédito: Da estabilização à crise financeira. In: MARCOLINO, Luiz Cláudio; CARNEIRO, Ricardo. Sistema Financeiro e Desenvolvimento no Brasil: do Plano Real à crise financeira. São Paulo: Atitude, 2010. p. 129-159.

RAMAKRISHNA, Saloni. Enterprise Compliance Risk Management: An Essential Toolkit for Banks and Financial Services. Nova York: Wiley, 2015, p. 20.

REUTERS. Citigroup gets massive government bailout. 2008. Disponível em: $<$ http://www.reuters.com/article/us-citigroup-idUSTRE4AJ45G20081125>. Acesso em: 2 jan. 2017.

RIBEIRO, Casimiro Antônio. Casimiro Ribeiro I (depoimento, 1975/1979). Rio de Janeiro, CPDOC, 1981. 121 p. dat.

ROE, Mark. Political Determinants of Corporate Governance: Political Context, Corporate Impact. Nova York: Oxford University Press, 2011.

. Structural Corporate Degradation Due to Too-Big-To-Fail Finance. University Of Pennsylvania Law Review, [s.1.], v. 162, n. 6, p.1419-1464, set. 2014. Disponível em: $<$ http://scholarship.law.upenn.edu/cgi/viewcontent.cgi?article=9445\&context=penn_law_r eview>. Acesso em: 3 jan. 2017.

SAES, Flávio Azevedo Marques de. A moeda, o crédito e o financiamento da produção. Estudos Avançados, [s.1.], v. 15, n. 41, p.77-90, abr. 2001. FapUNIFESP (SciELO). http://dx.doi.org/10.1590/s0103-40142001000100008

SALAMA, Bruno Meyerhof. Como Interpretar as Normas Emitidas pelo BACEN e CMN? Uma Resposta a Partir da Evolução do Modelo de Estado Brasileiro. Revista de Direito Bancário, do Mercado de Capitais e da Arbitragem, [s.i], n. 46, 2009. Disponível em: $<$ https://works.bepress.com/bruno_meyerhof_salama/32/>. Acesso em: 3 jan. 2017. 
. Regulação Cambial entre a Ilegalidade e a Arbitrariedade: O Caso da Compensação

Privada de Créditos Internacionais. Revista de Direito Bancário e do Mercado de Capitais, [s.1], n. 50, p.157-184, dez. 2010.

SALAMA, Bruno Meyerhof; PRADO, Viviane Muller. Operações de Crédito dentro de Grupos Financeiros: Governança Corporativa como Complemento à Regulação Bancária. In: ARAUJO, Danilo Borges dos Santos Gomes de; ARAUJO, Danilo Borges dos Santos Gomes de. Grupos de Sociedades: Organização e Exercício da Empresa. São Paulo: Saraiva, 2011. Disponível em: <https://works.bepress.com/bruno_meyerhof_salama/56/>. Acesso em: 3 jan. 2017.

SALOMÃo NETO, Eduardo. Direito Bancário. 2. ed. São Paulo: Atlas, 2014.

SALVIANO JÚNIOR, Cleofas. Bancos Estaduais: dos problemas crônicos ao PROES. Brasília: Banco Central do Brasil, 2004. Disponível em: $<$ http://www.bcb.gov.br/htms/public/BancosEstaduais/livro_bancos_estaduais.pdf $>$. Acesso em: 4 jan. 2017.

SCHNEIDER, Ben Ross. Hierarchical Capitalism in Latin America: Business, Labor, and the Challenges of Equitable Development. New York: Cambridge University Press, 2013.

SECURITIES AND EXCHANGE COMMISSION. PUBLIC LAW 107-56-OCT. 26, 2001. Uniting and Strengthening America by Providing Appropriate Tools Required to Intercept and Obstruct Terrorism (USA Patriot Act) of 2001. 2001. Disponível em: $<$ https://www.sec.gov/about/offices/ocie/aml/patriotact2001.pdf $>$. Acesso em: 5 jan. 2017

SHEARMAN \& STERLING LLP. The Re-Proposed Rule on Incentive-Based Compensation at Financial Institutions: Overview and Observations. [s.1]: Shearman \& Sterling Llp, 2016. Disponível em: $<$ http://www.shearman.com/ /media/Files/NewsInsights/Publications/2016/05/The-ReProposed-Rule-on-Incentive-Based-Compensation-at-Financial-Institutions-Overview-andObservations-CGE-050516.pdf>. Acesso em: 2 jan. 2017. 
SILVA, Fabiana Lima. As mudanças no padrão de gestão do Banco do Brasil: Uma análise crítica dos fundamentos. Planejamento e Políticas Públicas, [s.1], v. 34, p.35-66, 2010. Disponível em: $<$ http://www.ipea.gov.br/ppp/index.php/PPP/article/view/167/180>. Acesso em: 5 jan. 2017.

SILVA, Virgílio Afonso da; ROCHA, Jean-Paul Cabral Veiga da. A regulamentação do sistema financeiro nacional: o art. 192 e o mito da lei complementar única. Revista de Direito Mercantil, [s.1], v. 127, p.79-92, 2002.

SINGER, Paul. O Processo Econômico. In: REIS, Daniel Aarão. Modernização, Ditadura e Democracia: 1964-2010. Rio de Janeiro: Objetiva, 2014. p. 181-231. (História do Brasil Nação: 1808-2010).

SIQUEIRA, Francisco José de. Instituições Financeiras: Regimes Especiais no Direito Brasileiro. $8^{\circ}$ Encontro de Juristas Bancários de Expressão Oficial Portuguesa, [s.i], p.44-69, 2000. Disponível em: <http://www.bcb.gov.br/htms/public/8encjur/06 - francisco josé de siqueira.pdf $>$. Acesso em: 4 jan. 2017.

SMITH, Penelope; TAN, Nicholas. Total loss-absorbing capacity. Bulletin Of The Federal Reserve Bank Of Australia, Sydney, p.59-66, dez. 2015. Disponível em: $<$ https://www.rba.gov.au/publications/bulletin/2015/dec/pdf/bu-1215-7.pdf $>$. Acesso em: 5 jan. 2017.

TAVARES, Martus A. R.; CARVAlHEIRO, Nelson. O Setor Bancário Brasileiro: Alguns aspectos do crescimento e da concentração. São Paulo: FIPE-USP, 1985.

TAYLOR, Matthew. Institutional Development through Policy-Making: A Case Study of the Brazilian Central Bank. World Politics, [s.i], v. 61, n. 3, p.487-515, jun. 2009. Disponível em: $<$ http://scholar.harvard.edu/files/levitsky/files/taylor_banco_central_brasil_2009.pdf>. Acesso em: 1 jan. 2017 
TRUBEK, David; VIEIRA, Jorge Hilário Gouvêa; SÁ, Paulo Fernandes de. Direito, Planejamento e Desenvolvimento do Mercado de Capitais Brasileiro: 1965-1970. 2. ed. São Paulo: Saraiva, 2011.

VERÇOSA, Haroldo Malheiros Duclerc. Responsabilidade Civil Especial: Nas instituições financeiras e nos consórcios em liquidação extrajudicial (um estudo "de iure constituto" e de "lege ferenda"). São Paulo: Revista dos Tribunais, 1993.

YAZBEK, Otavio. Regulação do Mercado Financeiro e de Capitais. 2. ed. Rio de Janeiro: Campus, 2008. 